\title{
Erratum to: Decreased trophic position as a function of increasing body size of a benthic omnivorous fish from the largest freshwater lake in China
}

\author{
Yuyu Wang • Xiubo Yu • Jun Xu
}

Published online: 23 July 2011

(C) Springer Science+Business Media B.V. 2011

\section{Erratum to: Environ Biol Fish \\ DOI 10.1007/s10641-011-9808-0}

Unfortunately, there was a mistake in the unit of the amount of "Chlorophyll a" in Table 1. Instead of "mg $\mathrm{L}^{-1}$ ", the unit should be " $\mu \mathrm{g} \mathrm{L} \mathrm{L}^{-1}$ ".

The online version of the original article can be found at http:// dx.doi.org/10.1007/s10641-011-9808-0.

Y. Wang $\cdot X$. Yu $(\bowtie)$

Key Laboratory of Ecosystem Network Observation and Modeling, Institute of Geographic Sciences and Natural Resources Research, Chinese Academy of Sciences,

Beijing 100101, China

e-mail: yuxb@igsnrr.ac.cn

Y. Wang

Graduate University of Chinese Academy of Sciences,

Beijing 100049, China

J. Xu

Donghu Experimental Station of Lake Ecosystems,

State Key Laboratory of Freshwater Ecology and

Biotechnology of China, Institute of Hydrobiology,

Chinese Academy of Sciences,

Wuhan 430072, China 